\title{
GPS on the example of an auto-generating 3D model with free tolerance
}

\author{
GPS na przykładzie autogenerującego modelu 3D \\ z uwzględnieniem tolerowania swobodnego
}

\begin{abstract}
GPS, i.e. geometric product specification, is a graphical system consisting of symbols, rules, and definitions that describe the requirements for dimensions, shapes, profiles, directions, and positioning and milling of a finished product in a three-dimensional space. The paper focuses on the group of tolerances within the product shape, taking into account the so-called free tolerance. For the purposes of this work, a 3D model of the cylinder described using the functional dependencies, has been created, which is used to illustrate the concept of GPS in three-dimensional space. The CATIA engineering environment has been applied for this purpose and a suitable numerical parameters have been assigned to each of the dimensions and tolerances. The use of a self-generating 3D model makes it easier to illustrate the GPS concept by graphically displaying the resulting tolerance field. The autogenerating model has been used to verify the correctness of the piston gauge.
\end{abstract}

KEYWORDS: GPS, geometrical tolerance, free tolerancing, autogenerating $3 \mathrm{D}$ model

When designing a product, the type of technological process, in which the item is to be produced, is often overlooked. However, it is important to remember that the final product or the actual element is always different from the nominal element designed by a designer. The determination of the acceptable form of this difference is determined by GPS. The specification is thus in agreement between the constructor, the technologist and the metrologist as to the tolerance of the dimensions and the quality of the product [2].

A number of dimensional tolerances, including shape tolerances, are used in structural design. The constructors also use the so-called free tolerance. In situations where the tolerance values in documentation are high, it is difficult to accurately represent the tolerance field. For the purposes of this paper, an auto-generating shaft model was developed to summarize all the deviations introduced, and then to calculate the dimensions of both the lower maximum and upper maximum deviations [4]. Due to these calculations, the software can model the shaft and dimension tolerance field [3]. In addition, the auto-generating model was enriched with a knowledge database containing the most commonly used tolerances [7].

\footnotetext{
* Mgr inż. Paweł Wieroński (pwieronski@ath.bielsko.pl) - Akademia Techniczno-Humanistyczna w Bielsku-Białej
}

Subsequent parts present an example of the use of a parametric model.

\section{Evaluation of the accepted tolerances of the piston check using an auto-generating model}

Properly prepared auto-generating model can be used not only for didactic purposes - illustration of GPS issues - but also in everyday engineering practice. For the purpose of this paper, the 3D model of the double-sided piston check (fig. 1) was designed to verify the conformity of the tolerated hole in the finished product after the final machining with the assumptions. Diameter of the checked hole is:

$$
\varnothing 20 \pm 0,15=\varnothing_{19,85}^{20,15}
$$

The transient side of the test is marked with green paint, while the non-transient side with the red. This is a practical solution, because it allows the operator to immediately recognize which end of the test is being applied at the moment to the hole. The drawing tolerance of the hole forces the values of both diameters at the ends of the test. The diameter of the end of the test on the non-transient side must therefore have a maximum value of $\varnothing 20.15$, while on transient side, the diameter value should be at least $\varnothing 19.85$.

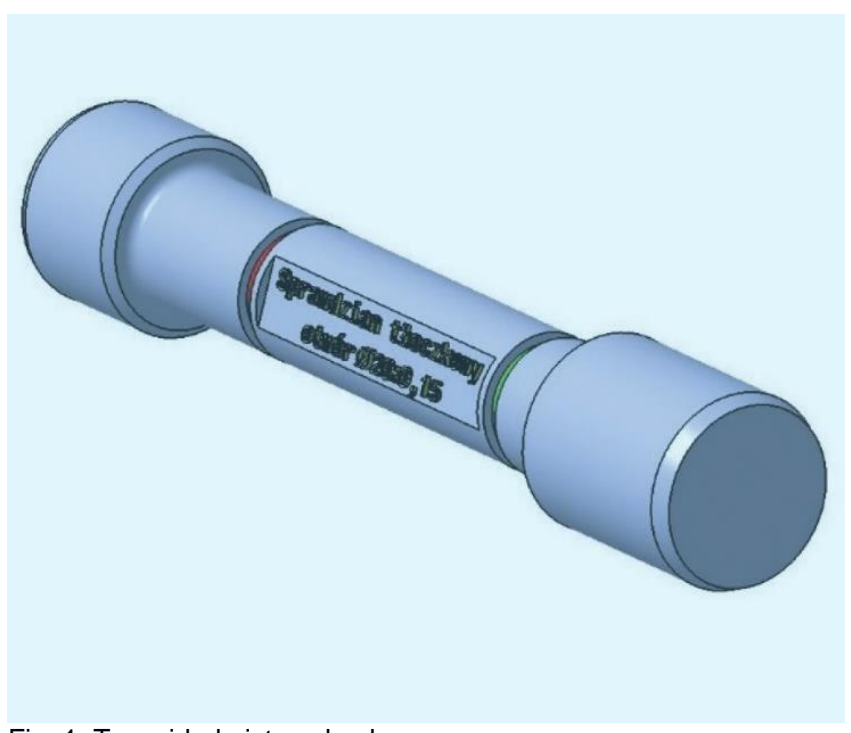

Fig. 1. Two-sided piston check 
As already mentioned, according to the GPS concept, the tolerance of its execution must be taken into account in the executive drawing of a properly designed check. It is also important to consider the tribological wear of the instrument.

One of the piston gauges encountered has a tolerance in the upper deviation (fig. 2). The prepared auto-generating model makes it easy to determine whether the tolerances applied meet the diameter requirements of the hole.
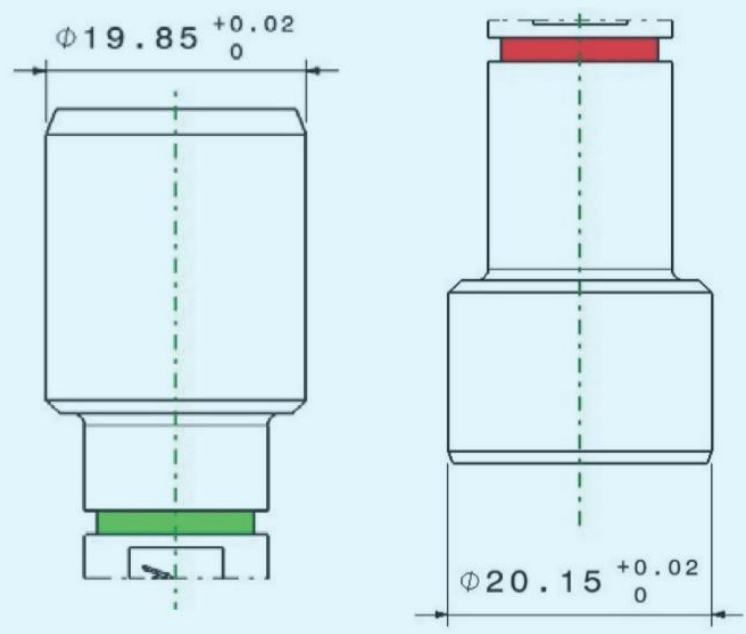

Fig. 2. Diameter values at the end of the check

It is immediately clear that the tolerance of both sides is incorrect, since it is possible to make a cross-sectional check with a lower limit deviation of 0 . Thus, the check is not taken into account in its daily work, since the diameter value equal to $\varnothing 19.85$ is actually the total consumption limit of the instrument. In practice, so-called instructions for the use of the control and measurement means are applied, which accurately determines the frequency of the control of indicated dimensions, but does not allow for the possibility of capturing early check wear between consecutive tests.

The standard PN-M-02140:1972 [5, 6] and ICAD tolerance calculator available on the Internet were used to generate the appropriate diameters at both ends of the check and corresponding tolerances.

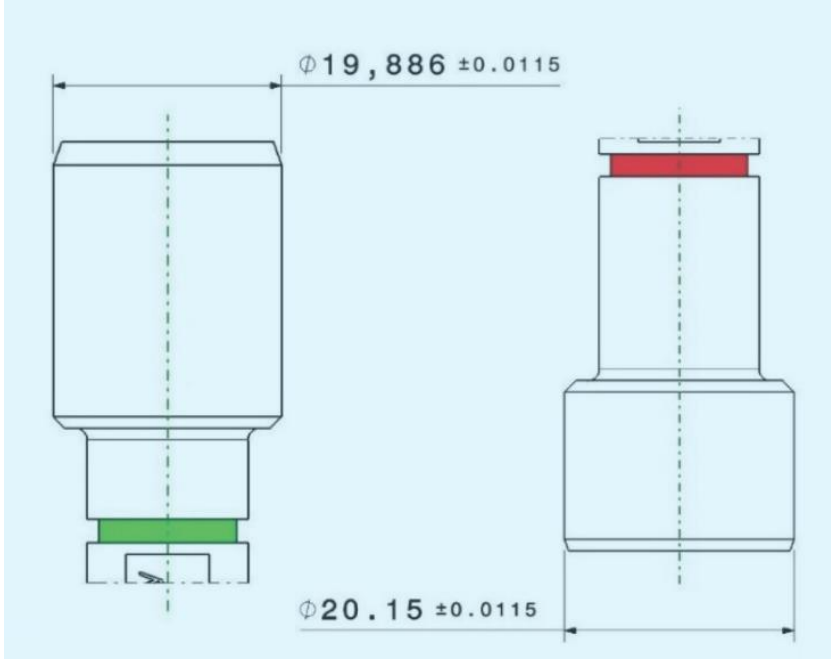

Fig. 3. Diameter values at the ends of the piston check generated by ICAD
After entering the hole diameter data with limit tolerances, the program returned the following diameter values (fig. 3):

- for the transition side $-\varnothing 19.886 \pm 0.0115$,

- for the non-transition side - $\varnothing 20.15 \pm 0.0115$.

As it can be seen, the generated diameter values differ from those currently used. For better visualization of this difference, a prepared auto-generating model was used. Fig. 4 clearly shows that the tolerance range currently used is below the normal tolerance range. This proves that the values of deviations are correct and that the two-sided piston check is to be modified.

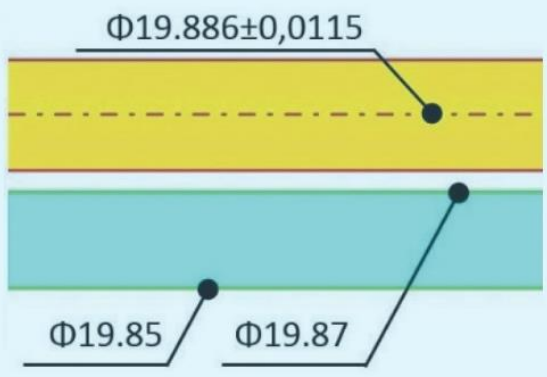

Fig. 4. Comparison of the check tolerance field

\section{Conclusions}

In today's engineering world, it is difficult to imagine a properly designed mechanical construction without providing adequate tolerance values when dimensioning the finished product. The use of the proposed autogenerating model allows for a very easy and clear way to illustrate the field of permissible dimensional tolerance in a three-dimensional space. However, it is essential to know the dimensions and tolerances of the GPS system.

Proposed solution cannot only be useful for teaching, but also - as shown in the example of the piston check allows for the verification of correct tolerances in everyday engineering practice.

In future, it is planned to create more developed auto-generating models that allow for the application and visualization of direction, positioning and beating tolerances for more complex cases.

\section{REFERENCES}

1. Humienny Z. „Tolerancje kształtu, kierunku, położenia i bicia ustalenia nowej Polskiej Normy". Cz. 1-2. Mechanik. 3 (2007): pages 160-164; 4 (2007)

2. Humienny Z., Berta M. „A digital application for geometrical tolerancing concepts understanding". 12 th CIRP Conference on Computer Aided Tolerancing. Procedia CIRP. 27 (2015): pages 264-269.

3. Humienny Z., Turek P. "Animated visualization of the maximum material requirement". Measurement. 45 (2012): pages 2283-2287.

4. Jakubiec W., Malinowski J. „Metrologia wielkości geometrycznych". Warszawa: WNT, 2004.

5. PN-EN ISO 14253-1:2014 - Specyfikacje geometrii wyrobów (GPS). Kontrola wyrobów i sprzętu pomiarowego za pomocą pomiarów. Część 1: Reguły orzekania zgodności lub niezgodności ze specyfikacjami.

6. ISO/DIS 1938-1:2011 - Geometrical product specifications (GPS). Dimensional measuring equipment. Part 1: Plain limit gauges of linear size.

7. Skarka W. „CATIA v5. Podstawy budowy modeli autogenerujących”. Gliwice: Wyd. Helion, 2009. 